University for Business and Technology in Kosovo

UBT Knowledge Center

Oct 27th, 4:45 PM - 7:15 PM

\title{
Application of Complex Adaptive Leadership Approach in Multinational Construction Company in Albania
}

\author{
Blerta Vula Rizvanolli \\ University for Business and Technology, blerta.vula@ubt-uni.net
}

Follow this and additional works at: https://knowledgecenter.ubt-uni.net/conference

Part of the Architecture Commons

\section{Recommended Citation}

Rizvanolli, Blerta Vula, "Application of Complex Adaptive Leadership Approach in Multinational Construction Company in Albania" (2017). UBT International Conference. 1.

https://knowledgecenter.ubt-uni.net/conference/2017/all-events/1

This Event is brought to you for free and open access by the Publication and Journals at UBT Knowledge Center. It has been accepted for inclusion in UBT International Conference by an authorized administrator of UBT Knowledge Center. For more information, please contact knowledge.center@ubt-uni.net. 


\title{
Application of Complex Adaptive Leadership Approach in Multinational Construction Company in Albania
}

\author{
Blerta Vula Rizvanolli ${ }^{1}$ \\ UBT - Higher Education Institution, Lagjja Kalabria, 10000 p.n., Prishtine, \\ Kosovo \\ blerta.vula@ubt-uni.net
}

\begin{abstract}
The vivid non-linear business environment of nowadays, enhances companies to embrace the complexity leadership approach, in order to remain competitive in a globalized industry. Maintaining their adaptive system is found to be the main challenge. This paper aims to analyze the up-to-date literature based on Complex Adaptive Leadership approach, focusing on Chaos Theory and Complexity Science. In addition a real-life case of a German company investing in real-estate sector in Albania is introduced. The highly dynamic environment of construction project depends on the information flow and interaction between project stakeholders, which is proved to impose high unpredictability, continuous disequilibrium and emergence. Butterfly Effect, Strange Attractors, Self-Organization, Emergence DecisionMaking, Feedback and over all Complex Behaviors of the Company Leadership are discussed considering the circumstances under which the company has terminated the agreement with General Contractor during the construction phase. Finally the consequences of these changes are disclosed and recommendations for improving future actions are proposed.
\end{abstract}

Keywords: Leadership, Complex Adaptive Leadership, Chaos Theory

\section{Introduction}

Over the last several years, the dynamic complex development of business environment require the organizations to cope with high level of uncertain, unpredictable, continually-changing and evolutionary circumstances in order to remain competitive and respond to market needs. The aim of this paper is to analyze the Leadership Behaviors under Complex Adaptive Leadership Approach using a real- life case of a German real-estate investor company operating in Albania.

The first section is dedicated to empirical review of up-to-date literature on Chaos Theory and Complexity Science. The initial scientific interest on explaining them, have been observed, when the traditional leadership approaches were not able to interpret the emerged phenomenon of nonlinearity, infocracy and polyarchy. The main attributes of Chaos Theory are described, focusing on Butterfly Effect and Strange Attractors. Further, an in-deep analyze of Complex Adaptive Systems, is undertaken introducing its most important characteristics. The idea of wide range behavioral leadership is portrayed through "Whole Leader" figure. While the complexity science is ascertain through similarities with human brain and human ecosystems. The literature review is completed by identifying the continuous need of Complex Adaptive Systems for SelfOrganization and Feedback.

On the second part, the profile of the Company, representing a German real-estate investor in Albania is presented followed by a narrative explanation of the parties involved in the project 
and their assigned responsibilities. A major change that occurred when the agreement with General Contractor was terminated in the middle of construction phase is prescribed laying the ground for further analysis of the case. The influence of Butterfly Effect in the company is found to be crucial for further development of the project. Negligence of initial conditions by the company leadership evolved in unpredictable outcomes. Meanwhile the other attitude of adaptive systems - Emergence, is proved to increase the project complexity triggering new results. This section also discusses the interaction of the company project stakeholders, their attitude for selforganizing and the leadership feedback approach.

Lastly, based on the literature review and real-case analysis, conclusion and recommendations on the approach and behaviors embraced by the company Leadership are drawn with the intention of re-shaping and re-adapting the project outcomes. On the meantime, limitation of the Complex Adaptive Leadership Approach to understand the brain development of agents is identified and future use of Brain Adaptive Leadership Approach is proposed.

\section{Theory Development}

In a highly ambitious global business environment, companies are struggling to maintain their complex dynamic processes and remain competitive. These fast lane developments require new leadership approaches to be able to adapt and respond to market needs, rapid change of technology and exceeded level of information.

Over the last years, several new approaches such as Complexity and Chaos Theories, Butterfly Effect, Strange Attractors, Emergence, Evolution and Complex Adaptive Systems (McMillan, 2008) are impacting the social sciences including management and leadership developments. Most of these theories are backing up the everyday changes and evolution of the business environment and the ability of the organizations to grow and develop simultaneously (Dimitriadis and Psychogios, 2016).

\section{Chaos Theory}

As an integral part of Complexity Science, Chaos Theory started about 40 years ago when the traditional cause-and-affect manner was not enough to explain latest systems developments (Olaniran et al., 2017). Usually, chaos is understood as a state of confusion, disorder and uncertainty. But actually, the theory studies the non-linear dynamic interactions that are developed in unpredictable way (Levy, 1994) and it implies that the whole system shifts depends from the changes and evolution of the surrounding environment (Dimitriadis and Psychogios, 2016). Schuldberg (2011) underline that Chaos Theory position itself contrary to conventional management which is based on linear thinking, predictable, stable and regular events, so the impact of an action has a proportional relation to the magnitude of the force which produce it.

While in Chaos Theory, this relation is disproportional. According to Frear (2011), if in the conventional management a project is deemed unsuccessful because it could not met the objectives, schedules, cost estimations, etc., in Chaos Theory, a project parameter can react to small changes in its initial conditions, which may create many variations of possible outcomes. Thus, the main attributes of this theory identified by Olaniran et al., (2017) are dependencies from initial conditions, positive feedback, major phase changes and strange attractors. 
McMillan (2008) ascertain that even that the chaotic systems seems to be unpredictable and erratic in behaviour, they still have their own internal hidden order (Singh and Singh, 2002), which is not calm, silent and static rather it's complex, complicated and have its own scheme of behaviours which creates the unique kind of order. They also agree for the main characteristics of the Chaos Theory to be: Butterfly Effect, Strange Attractors, adding also the edge of chaos, notion of order and disorder and fractals.

\section{Butterfly Effect}

Nijs (2014) who studied the Butterfly Effect from the engineering perspective defined it as a mechanism of complexity science, a science of non-linear complex and dynamic events, which depends on technological calculation to reveal its secrets.Singh and Singh (2002) explain that this effect, which has been scientifically described by Edward Lorenz in 1950's while trying to understand the chaotic behaviour of weather system, is caused by the minor irregularities in the initial condition of the project, which may cause major consequences by the end of it. McMillan (2008) highlights that in Butterfly Effect, even the smallest things in the system do matter, so it is almost impossible to accurately determine the real degree of long-term outcomes in the series of the events.

Meanwhile, at the same time, strange attractors have been identified, which according to Robertson and Combs (2014) indicate that while the complex systems can shortly move through a specific order, they still comprise the attitudes of chaotic systems and never settle down. These effects are hugely noticed in the construction industry especially in multinational projects, because of complex processes, physical distances between stakeholders, cultural, ethical and technological differences.

\section{Complexity Leadership Theory}

On the other hand, by observing the actual business environment, it can be easily noticed the high amount of pressure for innovation and creativity while the efficient approaches on everyday industries changes are more than required. The trend in leadership science is slowly shifting from oligarchic approach, to polyarchic one (Obolensky, 2014).Considering this, it has been perceived the influence that everyday emergent individual interactions of agents have on enhancing business performance of the organization, known as Complexity Leadership Theory (Lichtenstein et al. 2006; Psychogios et al., 2016).In the best case, these dynamic individual actions, if they are not interrupted from the company's bureaucracy, are linked to each other to create a powerful outcome.

Psychogios and Garev (2012) emphasize that this theory requires from leaders to exhibit a wide range of behaviours, for a successful response to unpredictable situation that occurs in the organizations. The "Whole Leaders" as named by Dotlich (2006), shall be able to lead with their Head - providing strategy, objectives and motivation; Heart - involving, collaborating and developing others; and Guts-undertaking the right decisions based on clear personal values.

In a recent study, Arena and Uhl-Bien (2016) underline that based on Complexity Leadership Theory an adaptive space occurs between two main systems in nowadays companies: Operational System - which enhance the performance through formality, schedules, standardization and results and Entrepreneurial System which pushes the boundaries of social and technological innovation and growth. This adaptive space enables linkage of clusters across systems by overcoming the bias that operation system should avoid the creative energy of entrepreneurial 
system (Fig.1). Lichtenstein (2016) goes further by identifying the dynamic similarities that complexity shares with entrepreneurship such as emergence and creativity, opportunity and new potentials.

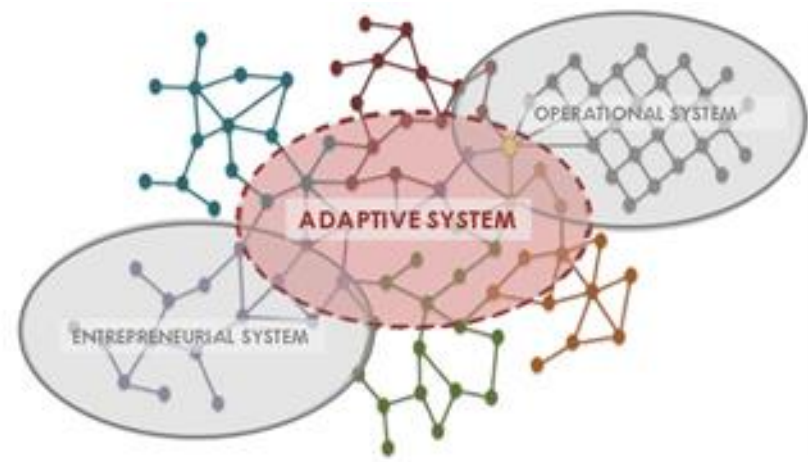

Fig. 1 Interaction of Adaptive System between Operational and Entrepreneurial System

According to McMillan (2008) a complex adaptive system as a living system involves social and biological systems, human and insect organizations, the human brain and immune system, ecosystems, economies and stock markets. They all impose the same characteristics of large number of self-organizing agents, which cooperate in a non-linear structure, which are continually learning but don't have a controlling mechanism, which are used to exist at the edge of chaos, by adapting and changing the circumstances into their advantage.

Moreover Hazy (2008) stresses that Complex Environment Systems shall continually adapt, configure and re-configure its multi-agents capabilities in order to be able to effectively follow the market changes, which enquire the meta-capability of leadership distributed throughout the entire organization (Fig.2). Triggered toward successful results, Psychogios and Garev (2012) propose a holistic approach of the complex organization environment, which requires fast and complex decision making process rather than focusing on people and work processes.

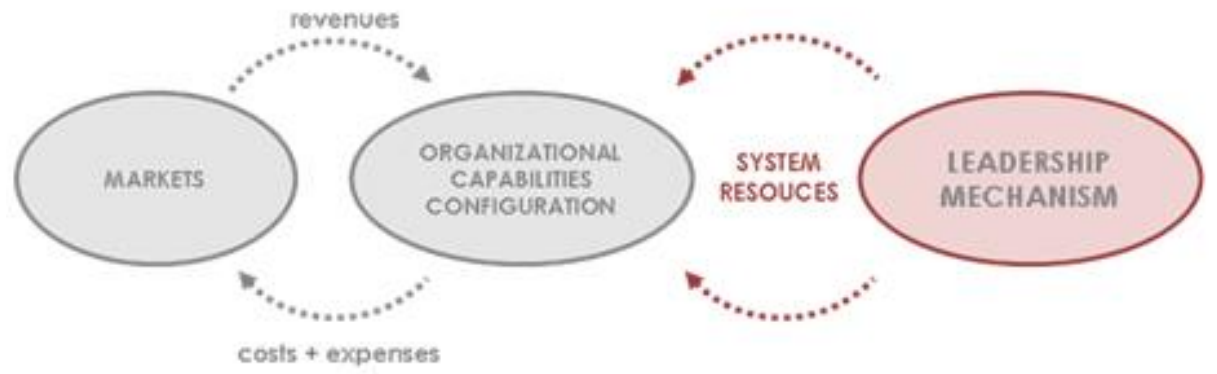

Fig. 2 Leadership reaction toward market needs

Actually, complexity science tries to bring the complex, complicated and multi-layered systems closer to the way that human brain works. Same as an organization, according to McMillan (2008), the human brain is made up of millions individual agents - neurons, which operate in their sub systems - cerebellum, amygdale or the hypothalamus, but they all cooperate and are coordinated in a very complex way that create a living system of the brain. She has identified the 
key concepts of complexity science as: complex adaptive systems, self-organizing systems, emergence and co-evolution. Similar concepts are identified by Obolensky (2014): Selforganization, inter-relatedness, adaptiveness and emergence. On the other hand Perez and Batten (2006)linked the science with the human ecosystem, which exhibit complexity characteristics such as: Emergence, Path Dependency, Ever Changing Equilibrium and Adaptation.

Apart from the energy that flows in human ecosystem, Steppet al. (2003) raise the case of tremendous amount of information that flows during the interaction of agents which under the volatile, uncertain, complex and ambiguous conditions, Dimitriadis and Psychogios (2016) called it Infocratic system. They continue by suggesting to leaders new approaches for infocracy toward continuous adaptation and not toward a single optimum outcome as it used to be in bureaucratic systems. The same is suggested by Obolensky (2014) according to whom, the time of typical organizational chart which used to present how the information flows in the company, who is reporting to whom, how the jobs are done is forever gone, because the trends of adaptive systems are showing more cross-functionality, informality and flatterer hierarchies which are difficult to be explained in the simple chart of the organization. He used a schematic explanation to express the changing trends of working systems from well structures companies to Complex Adaptive Systems (Fig.3).

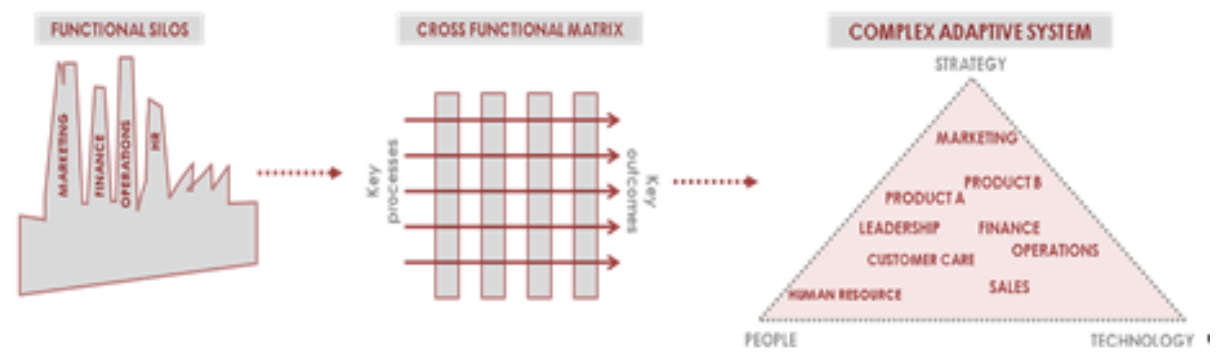

Fig. 3 Changing Trends of Working Systems

A successful Complex Adaptive Leader Model - is defined by Obolenskly (2014) who says that nowadays leaders shall be able to move from coaching, to giving directions, consulting or delegating role depends from the changing situation and sometimes exercise more than one attractor at a time depends from a complexity level of person he is dealing with (Fig.4). The entire circle is followed by a complicated decision making process which needs to be undertaken quickly and several times during a short period of time. McMillan (2008) has given the example of Ricardo Seemler from Semco - one of the few Complex Adaptive Companies in the world, who said that self-organizing approach followed by the company, enables him to prioritize information and take fast decisions.

The same conclusion was driven by Psychogios and Garev (2012) who emphasize that by adopting the Complex Adaptive Leadership behavior the company increases the capacity for faster decision making, constructive frame for innovation and adaptability toward market needs. This is being in deeply analyzed by the Neuroscience which helps understanding the leadership attitude and how the leader's brain work toward an effective and efficient decision making process (Dimitriadis and Psychogios, 2016). 


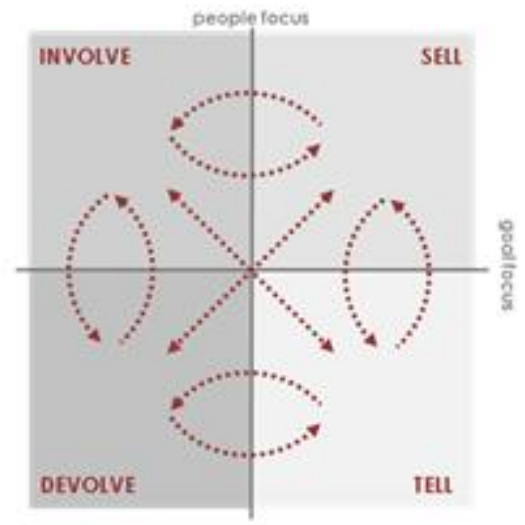

Fig. 4 Complex Adaptive Leadership - Strange Attractors

\section{Leadership in Construction Industry}

Leadership in construction Industry is well known for its dynamic complexity as the systems of implementing the projects are unique and involve a large number of stakeholders with different objectives toward the project outcomes. It includes all the characteristics that Morrison (2010) assigned to complex leadership such as interactions, connectivity, networking and relationships which enhance the projects operational effectiveness. In one side this advocates distributed leadership which is applied in ever-changing and unpredictable environments such as construction sites and on the other side, being a human oriented industry, it suggest employee's voice and creativity empowerment. These types of systems have the ability to self-organize, as long as the relationships between agents are leaded by never-ending feedback loop (Dimitriadis and Psychogios, 2016). Obolenskly (2014) ascertain that the only tolerance for ambiguity and chaos in the system is the need for unambiguous feedback which he identified to be Hard Feedback - Operational / Financial and Soft Feedback - Behavioural.

To give and receive the personal feedback Dimitriadis and Psychogios (2016) suggest a threefold approach: Keep it Informal, Specific and Benefit Driven. While for the organizational feedback, Obolenskly (2014) propose the 360 degree approach which is being used on daily basis in nowadays companies.

The above empirical review of literature on complex dynamic systems, chaos theory, complexity science and its concepts as well as complex adaptive leadership would be further facilitated to discuss the leadership case of a multinational real estate investment company operating in Albania, which has undergone through several changes during the construction stages.

\section{Analysis of Company Examples}

\section{Organization and Project Introduction}

The German operates in real estate sector in Albania since 2008. The project they are investing on comprises construction of 17 office buildings that will be rent to final users, with the complete 
related infrastructure including roads, landscape, drinking water and waste treatment plants. The overall investment is estimated at $€ 100$ million. The project is divided in five construction phases. The preparation stage started in 2008, considering all the necessary designs, plans and permits to start construction which had its ground-break three years later. The general contractor was a Greek company specialized in large and complex construction in the region, performing with Albanian subcontractors.

The project comprehends an unusual, unique and vivid environment of different mindsets of parties involved. German, Albanian and Greek engineers exhibit dissimilar working culture and performing standards in the construction industry. Albanians are more focused in progress in the time-frame of construction site, providing fast and not well-planned solutions during the process which may later cause many issues. While the Germans prefer to take time and plan everything in advance, especially taking in consideration all the risk related to investment in developing countries. Greek engineers are experienced with the German attitude of working, but as they have been agreed for lump-sum contract limited to 22 months, on several occasions they supported Albanian attitudes.

Responsibilities and authorities were distributed to different parties involved in the project. The client as a main decision-maker is located in Germany. Construction company headquarters and engineering staff was located in separate offices in Athens and Thessaloniki while the blue collar employees were sitting in construction site. Other designing responsible engineers were located in Germany, Austria and Albania. Additionally, supervising company is required by Albanian Construction Law to control and inspect the works. Most of the sub-contractors were located in Albania while the suppliers differ from the region and several European Countries.

\section{Case Analysis}

As it is highlighted above, multinational construction projects possess high level of complexity both in design and in production stage. Interaction between predictability and unpredictability, order and disorder and regularity and chaos can be easily distinguished. This industry is characterized by its messiness and continuous change (Khan et al., 2016).

The German investment project is characterized for its complicated organization structure where according to Morrison (2010) parties are urged to interact, stay connected to each other and develop networking and relationships. It is a purely infocratic environment that include enormous amount of drawings, emails, minutes of meetings, images, schedules, tables, specifications, contacts, permits, orders and changes of orders, reports, invoices and payments created during designing, construction and operating phase. These data that are transferred between project participants in daily basis generate a chaotic system that reacts even to the smallest changes of the pattern.

Considering the time-frame contract limited to 22 month for finalizing the first construction phase, the initial mistakes such as misinterpretation of information, delays in design approvals, and difficulties in employee trainings and engagement have emerged a Butterfly Effect that caused delays in implementation and as a result termination of the contract with general contractor in the middle of construction works. This effect was further increased, because, meanwhile, the organization was undertaking a massive marketing campaign, so changing of general contractor, has negatively impacted the future clients of the buildings and triggered the investor to question-mark the continuity of the project. This effect was so powerful, because of the interconnected complexity of the project and it was almost impossible for the leadership to predict how the future events would be unfolded based on their initial conditions and how the project stakeholders would react (McMillan, 2008). 
The outcomes of the Butterfly Effect, may be explained by a study undertaken recently from Qazi et al. (2016) which ascertain that in the complex construction projects, the managers do not consider all the risk factors since the commencement stage of the project and they usually rely on their intuition and previous experience while dealing with risk assessment. They further suggest that in this type of projects it is important to visualize the synergy between project complexity and complexity driven risk in order to prioritize risk and chose the proper risk mitigation strategy (Ramasesh and Browning, 2014).

On the other hand, as indicated by literature review (Psychogios and Garev, 2012; Dotlich, 2006), in a complex adaptive systems, it is requires from leaders to manifest a wide range of behaviours by providing strategic objectives, enhance collaboration and development of project participants and undertake the right decisions that will benefit the project outcomes.

Under the created circumstances in the project, the German General Manager, was in between choosing to continue the construction with the same general contractor knowing that there will be cost and time overruns, while risking other unforeseen events, or chose to change the contractor company, understanding that there will be additional time needed to finalize the project and deal with client's opinion on investor's financial sustainability. He was undergoing tremendous amount of pressure from all agents involved in the project: Investor - interested to insure success of its investment; Employees - eager to keep their job positions; Albanian politicians - interested to keep this large German investor within the country and Clients uncertain whether the project will be completed and if its competitive advantage are worth paying for. According to Crooke et al. (2015) while facing the so called "Tragedy of Choice" the managers of complex adaptive organizations shall integrate their individual, societal and stakeholder's values into the evolving organizational values considering the financial performance, product quality, social responsibility and environmental stewardship. The same was identified by Psychogios and Garev (2012) as a holistic approach of decision making process. Anyway, in a study presented lately by Apenko and Chernobaeva (2016), it is concluded that nowadays managers have not yet mastered the personal leadership behavioural of implementing different strategies when dealing with mismatched situations, raising the issue of poorly understood directions triggered by complexity science.

Yet another identified attitude of complex adaptive systems is Emergence (Psychogios and Garev, 2012; Obolenskly, 2014) as a fundamental component of complexity which examines the emergence of new orders in dynamic environments. Lichtenstein (2016) has highlighted that emergence is a process driven by intention, generates an emergent outcome and it increases the capacity of the system. From the emergence perspective, change is a matter of generating a new, more desirable direction (Nijs, 2014).

In the German project, after termination of agreement with main contractor, the investor found itself in front of an emergent complicated situation. Several new solutions were explicated to overcome the turmoil. But, considering the above mentioned conditions under which the project was going through, the investor decided to establish an internal construction company that will continue the intermitted work of previous contractor. While undergoing this difficult decisionmaking process, the leadership was conscious for the implementation complications that accompany new arrangements, but as highlighted by McMillan (2008) emergences are the processes that lead to development of something even more complex and much richer than the original one. It is a process highly related to coordination, interaction, learning process, problemsolving, trust-building and changes of routine(Bygballe et al., 2016).

Complexity thinking is not based on planning and control but on directing evolution to acceptable areas (Lehtiranta , 2011). On the other hand, the emergent situation arouse in the project, was also meant to be the result of over controlling of general contractor, lack of trust and highly bureaucratic procedures imposed by the investor. Obolenskly (2014) raise the voice for Self- 
Organization as the fundamental aim of the Complex Adaptive Leadership which allows thriving of polyarchy and remove strains and stresses. Similarly, Apenko and Chernobaeva (2016) claim for allowance of self-organization, self-objective and self-control as a main competence of Complexity Leadership.

Furthermore White et al. (2016) encourage understanding of leadership as a network of formal influence and informal social relations rather than individualized heroic approach. The collaborative and ethical approach is being persuaded by both American Society of Civil Engineers and European Council of Civil Engineers in their vision for the future developments of construction industry. As it is emphasized above construction is a human based industry and human interaction is a key factor of project performance, so Lehtiranta (2011) prove that in such complex construction projects, apart from performance risk, relational risk has a major impact in project success as the goals are to minimize the ambiguity and uncertainty. Ochieng et al. (2013) ascertain that construction leaders shall be able to understand the unpredictability of working environment especially when dealing with multi-cultural teams. They should impose superior interpersonal skills and understand individual's culture, values and contributions as well as create the positive and supportive environment.

This leads to another substantial issue of changes happened in the Project - Feedback. As highlighted from the empirical review section (Obolenskly, 2014; Dimitriadis and Psychogios, 2016), hard and soft Feedback approaches are an essential part of complex systems that ensure their adaptive stage to be smooth and uninterrupted. In the German project, an obvious concern was lack of feedback, from Contractor to Investor. Even though their representatives were both sited in the same construction site, the investor who was responsible for project design was keep pulling the strings of contractor to finish the project on time, without considering its objectives on possible project costs and time overruns claimed by contractor. Henderson et al. (2013) ascertain the need for further efforts in improving the formal and informal feedback loop especially between design and construction phase as they found it to be the major obstacle for the unmet objectives of construction projects. Nijs (2014) goes a step further by proposing leadership practices that will foster creativity in such environments by making them likable and acceptable: empower creativeness, create a peer culture, free up communication, create a learning environment and get the best from previous experiences.

\section{Conclusions \& Recommendations}

In a complex, dynamic, forever-changing business environment where everyone is committed to innovation and creativity, it is a challenge for companies to remain competitive even though this is becoming a normal habitat. Unpredictability, uncertainty, disequilibrium, non-linear interactions, emergence, evolution are all characteristics of everyday working life which science is attempting to explain by comparing them to natural events of different ecosystems.

The paper has been focused on analyzing the Complex Adaptive Leadership through understanding of Chaos Theory and Complexity Science. An empirical up-to-date literature review has contributed to identify the key components of the dynamic complex systems which have been further analyzed by attributing their specifics to the example of German Real Estate Investment Company operating in Albania.

Construction industry is highly fragmented and continuously striving to improve speed, efficiency, cost, quality, safety and technology. In the last two decades, it has crossed the national and regional borders being unlocked to global competitiveness Ochieng et al. (2013). The crosscultural and multinational influence has been added-up to already complex environment of construction project making the adaptation process more enthralling. 
As complex adaptive systems, construction projects impose the main features assigned by complexity science such as: non-linear individual interaction of agents, self-organization, emergence, adaptiveness, co-evolution and ever changing equilibrium (Perez and Batten, 2006; McMillan,2008; Obolensky, 2014). They are highly human and information oriented systems, so for this reason they tend to utilize cross-functionality, informality and flatterer hierarchies. Considering their multilayered chaotic complexity, construction organizations may easily be influenced by phenomenon such as Butterfly Effect and emergence which require for leaders to embrace strong interpersonal skills and wide range of behaviours to overcome the everyday challenges.

The German project under surveillance has gone through several complicated situations during its construction phase, which has ended-up by terminating the agreement with general contractor. This has been interpreted as an outcome of the Butterfly Effect initiated from the commenced mistakes such as misinterpretation of information, delays in design approvals, and difficulties in employee trainings and engagement which has further affected the clients and investor's perspective toward project success. These emergent circumstances led to creation of new internal construction company by the investor. Finally the General Manager has been replaced leaving behind a considerable amount of cost and time overrun.

Building up on the literature review and project details provided on the previous paragraphs, it is obvious that Investor's leadership lacked to exhibit Complexity Adaptive Leadership behaviours. Many authors (Lehtiranta, 2011; Ochieng et al., 2013; Obolenskly, 2014; White et al., 2016;) pay special attention to self-organization as well as collaboration and interaction between parties involved in the complex systems whichin case of German project were eventually missing. Even though Apenko and Chernobaeva (2016) have ended up in a conclusion that construction managers have not yet overcome the traditional leadership and that additional effort shall be make to adapt to the complexity leadership behavioural trends.

By further analyzing this project, it has been observed the insufficient and inappropriate feedback process developed during construction phase. Henderson et al. (2013) ascertain that formal and informal feedback should be an inevitable component especially between design and construction phase, while Dimitriadis and Psychogios, (2016) and Obolenskly (2014) encourage for three-fold and 360 degree feedback approach for successful project outcomes.

From the undertaken analysis of the German Investment Project, using the Complex Adaptive Leadership approach, it may be derived that certain changes in adapting the complexity leadership behaviours would result in more preferable project outcomes. Furthermore, additional case examination using Brain Adaptive Leadership approach proposed by Dimitriadis and Psychogios, (2016) may lead to more accurate behavioural judgment and effective project outcomes.

\section{References}

1. Apenko and Chernobaeva (2016) The Influence of Complex Adaptive Leadership on the Efficiency of Business Management. Proceedings of The European Conference on Management, Leadership \& Governance, p.17-24.

2. Arena and Uhl-Bien (2016) Complexity Leadership Theory: Shifting from Human Capital to Social Capital. People \& Strategy, 39(2), p. 22-27. 
3. Bygballe et al. (2016) Coordinating in construction projects and the emergence of synchronized readiness. International Journal of Project Management, 34(8), p.14791492.

4. Crooke et al. (2015) Leadership in a Complex World: How to Manage "The Tragedy of Choice". Organizational Dynamics, 44(2), p.146-155.

5. Dimitriadis and Psychogios(2016) Neuroscience for leaders (1st ed.). Kogan Page

6. Dotlich (2006) Developing CFOs as Whole Leaders.(Cover story). Financial Executive, 23(6), p. 36-41.

7. Frear (2011) The effect of change on management planning: Applying chaos theory.International Journal of Business and Social Science, 2(14), p.57-66.

8. Hazy (2008) Toward a theory of leadership in complex systems: Computational modeling explorations. Nonlinear Dynamics, Psychology, and Life Sciences, 12(3), p. 281-310.

9. Henderson et al. (2013) The need to improve double-loop learning and design-construction feedback loops. A survey of industry practice. Engineering Construction \& Architectural Management, 20(3), p. 290-306.

10. Khan et al.(2016) Managing information complexity using system dynamics on construction projects. Construction Management \& Economics, 34(3), p.192-204.

11. Lehtiranta (2011) Relational Risk Management in Construction Projects: Modeling the Complexity. Leadership \& Management in Engineering, 11(2), p. 141-154.

12. Levy (1994) Chaos theory and strategy: Theory, application, and managerial implications. Strategic Management Journal, 15(S2), p.167-178.

13. Lichtenstein (2016) Emergence and Emergents in Entrepreneurship: Complexity Science Insights into New Venture Creation. Entrepreneurship Research Journal, 6(1), p. 43-52.

14. Lichtenstein et al. (2006) Complexity leadership theory: An interactive perspective on leading in complex adaptive systems. Emergence: Complexity \& Organization, 8(4), p. 212.

15. McMillan (2008) Complexity, management and the dynamics of change: Challenges for practice. Routledge.

16. Morrison (2010) Complexity Theory, School Leadership and Management: Questions for Theory and Practice. Educational Management Administration \& Leadership, 38(3), p. 374-393.

17. Nijs (2014) Imagineering the Butterfly Effect: Transformation by Inspiration. The Hague: Eleven International Publishing.

18. Obolensky (2014) Complex adaptive leadership: Embracing paradox and uncertainty. Gower Publishing, Ltd.

19. Ochieng et al. (2013) The effect of cross-cultural uncertainty and complexity within multicultural construction teams. Engineering Construction \& Architectural Management, 20(3), p. 307-324.

20. Olaniran et al. (2017) Chaos Theory: Implications for Cost Overrun Research in Hydrocarbon Megaprojects. Journal of Construction Engineering \& Management, 143(2), p.1-8.

21. Perez and Batten (2006) Complex science for a complex world (1st ed.). Canberra: ANU E Press.

22. Psychogios and Garev (2012) Understanding complexity leadership behaviour in SMEs: Lessons from a turbulent business environment. Emergence: Complexity and Organization, 14(3), p.1-22. 
23. Psychogios et al. (2016) A three-fold framework for understanding HRM practices in South-Eastern European SMEs. Employee Relations, 38(3), p. 310-331.

24. Qazi et al. (2016) Project Complexity and Risk Management (ProCRiM): Towards modelling project complexity driven risk paths in construction projects. International Journal of Project Management, 34(7), p.1183-1198.

25. Ramasesh and Browning (2014) A conceptual framework for tackling knowable unknown unknowns in project management. Journal of Operations Management, 32(4), p.190-204.

26. Robertson and Combs (2014) Chaos theory in psychology and the life sciences, Psychology.Press, Hove, U.K.

27. Schuldberg (2011) Chaos theory and creativity. Encyclopedia of creativity

28. Singh and Singh (2002) Principles of Complexity and Chaos Theory in Project Execution: A New Approach to Management. Cost Engineering, 44(12), p. 23-33.

29. Stepp et al. (2003) Remarkable properties of human ecosystems. Conservation Ecology, 7(3).

30. White et al. (2016) Pluralized leadership in complex organizations: Exploring the cross network effects between formal and informal leadership relations. Leadership Quarterly, 27(2), p. 280-297. 